\section{Endotracheal Tube Holders and the Prone Position: A Cause for Concern}

\section{To the Editor:}

We read with interest the paper by Fisher et al $^{1}$ regarding the methods for securing endotracheal tubes. The authors should be congratulated for a carefully performed experiment in a model of the head and upper airway. We noted the increase in pressure exerted by the commercially available devices, which the authors reported as not clinically important. Although the authors used an elaborate model for simulating the patient and patient movements, the impact of the pressure on skin integrity could not be truly appreciated.

In recent months, with the increase in the use of prone positioning following publication of the PROSEVA study, ${ }^{2}$ we have noted that the use of these commercially available devices can be associated with significant facial ulceration. Skin breakdown and pressure ulcers on the forehead, chin, abdomen, and extremities have been reported to occur more frequently in patients placed in the prone position. ${ }^{3,4}$ This is largely due to body areas with little subcutaneous tissue and pressure: bone and skin versus the bed surface. The tops of the feet, knees, and elbows also seem to be commonly involved.

The authors did not test devices in the prone position, and the model likely could not approximate the changes in facial edema associated with this position. Facial edema is a common experience with the prone position and often leads to a return to the supine position, secondary to concern of the family and staff. Similarly, it is likely that manufacturers have not considered the use of these devices in the prone position and how, with time, facial edema probably significantly changes the pressure profile.

We observed significant facial ulcers in 3 patients using the Hollister device in the prone position. In all 3 cases, the ulcers required treatment. The first patient was an obese pregnant woman with severe ARDS and suspected H1N1 influenza. She was transferred from another hospital, where she had been managed for $6 \mathrm{~d}$. She developed skin ulcers on both cheekbones after $3 \mathrm{~d}$ of prone positioning (Fig. 1). The second patient developed ARDS following intraabdominal sepsis and aspiration pneumonia. He had a normal body habitus and developed ulcers after $4 \mathrm{~d}$ of prone posi- tioning. In this case, the skin ulcers were similar to the first case (Fig. 2). The third patient was an 84-y-old man with esophageal cancer who underwent an esophagectomy. He aspirated on day 4 postoperatively

and developed severe ARDS $\left(\mathrm{P}_{\mathrm{aO}_{2}} / \mathrm{F}_{\mathrm{IO}_{2}}\right.$ $<80 \mathrm{~mm} \mathrm{Hg}$ ). After $<36 \mathrm{~h}$ of prone positioning, he developed an ulcer on the left side of his face that mimicked the outline of the Hollister endotracheal tube holder. This

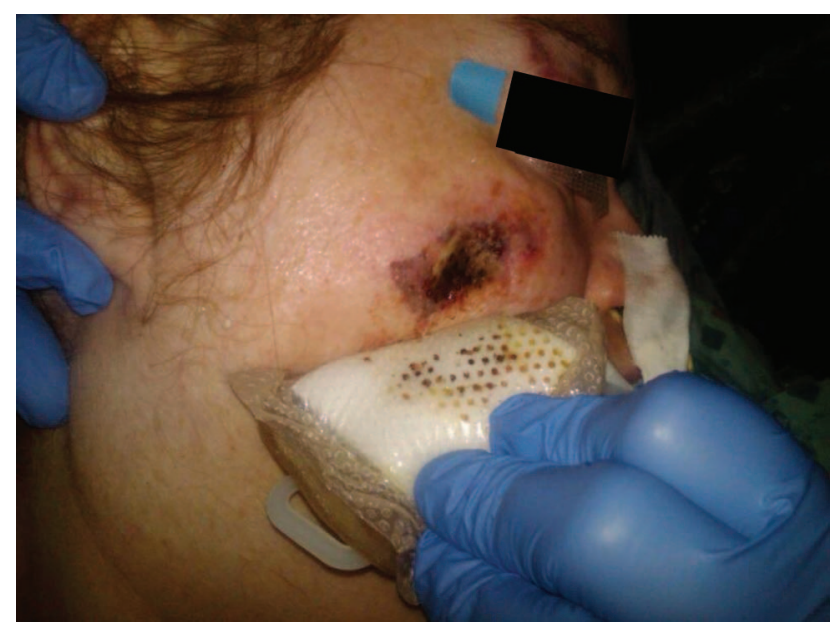

Fig. 1. Pressure ulcer at the edge of the endotracheal tube holder in patient 1.

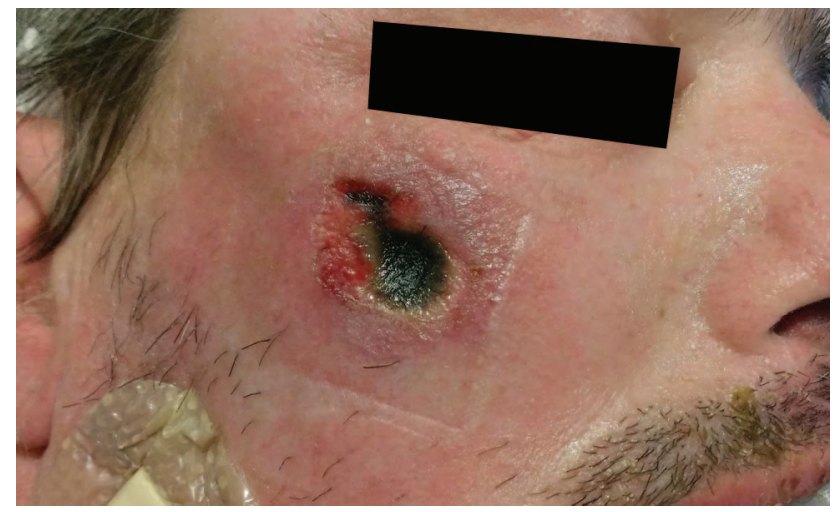

Fig. 2. Pressure ulcer at the edge of the endotracheal tube holder in patient 2.

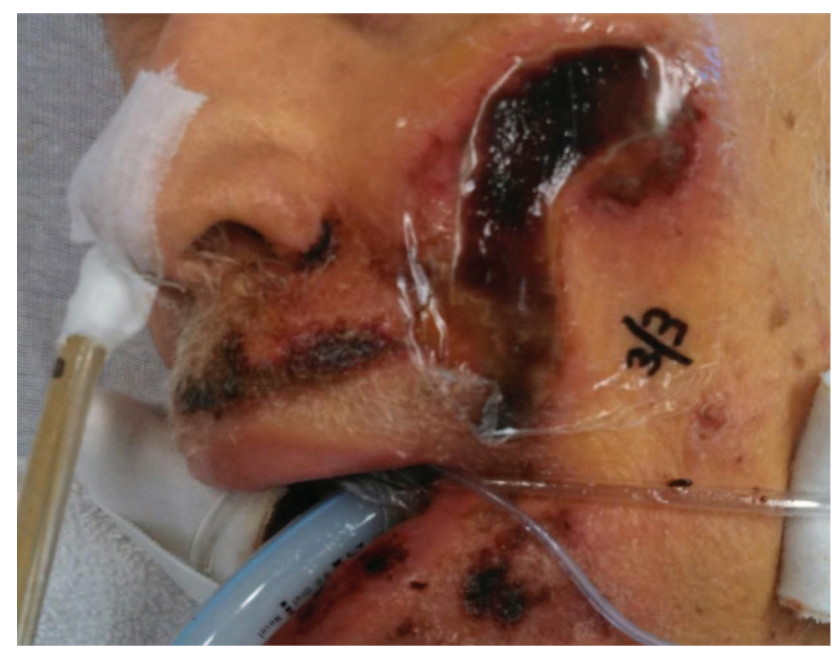

Fig. 3. Pressure ulcer appearing to reflect the shape of the endotracheal tube holder in patient 3. 
patient had poor nutritional status and cancer cachexia, predisposing him to skin integrity issues (Fig. 3).

Others have noted similar issues, and Jackson et $\mathrm{al}^{5}$ proposed specific padding of the head and face to reduce ulcers during prone positioning. Therapists should be cognizant of the potential for these types of facial ulcers (usually associated with mask ventilation), which have been identified by Medicare as avoidable complications. ${ }^{6}$

Facial edema associated with the prone position clearly increases the risk of airway complications regardless of the method of tube fixation. Clinicians should be vigilant to maintain airway position and prevent skin breakdown. The data obtained by Fisher et $\mathrm{al}^{1}$ and our observations urge extreme caution during use of commercially available tube-fixation devices for patients placed in the prone position.

\section{Dina Gomaa RRT}

Richard D Branson MSc RRT FAARC

Department of Surgery

University of Cincinnati

Cincinnati, Ohio

The authors have disclosed no conflicts of interest.

DOI: $10.4187 /$ respcare. 03908

\section{REFERENCES}

1. Fisher DF, Chenelle CT, Marchese AD, Kratohvil JP, Kacmarek RM. Comparison of commercial and noncommercial endotracheal tube securing devices. Respir Care 2014;59(9):1315-1323.

2. Guérin C, Reignier J, Richard JC, Beuret P, Gacouin A, Boulain T, et al. Prone positioning in severe acute respiratory distress syndrome. N Engl J Med 2013;368(23):21592168.

3. Sud S, Friedrich JO, Taccone P, Polli F, Adhikari NK, Latini R, et al. Prone ventilation reduces mortality in patients with acute respiratory failure and severe hypoxemia: systematic review and meta-analysis. Intensive Care Med 2010;36(4):585-599.

4. Lee JM, Bae W, Lee YJ, Cho YJ. The efficacy and safety of prone positional ventila- tion in acute respiratory distress syndrome: updated study-level meta-analysis of 11 randomized controlled trials. Crit Care Med 2014;42(5):1252-1262.

5. Jackson ME, Verano JX, Fry JE, Rodriguez AP, Russian C. Skin preparation process for the prevention of skin breakdown in patients who are intubated and treated with RotoProne. Respir Care 2012;57(2):311-314.

6. Zaratkiewicz S, Whitney JD, Lowe JR, Taylor S, O'Donnell F, Minton-Foltz P. Development and implementation of a hospital-acquired pressure ulcer incidence tracking system and algorithm. J Healthc Qual 2010;32(6):44-51.

\section{Endotracheal Tube Holders and the Prone Position: A Cause for Concern-Reply}

\section{In Reply:}

We appreciate the comments by Gomaa and Branson concerning their patients who developed pressure sores during prone ventilation and how it relates to the findings of our study. ${ }^{1}$ The authors are correct that the effects of prone positioning were not evaluated in our study. Prone positioning and facial edema, although both important factors in skin integrity around the airway, were not within the scope of our study. However, data derived from our observations could be used to identify airway-securing devices that had pressure points in the supine position. The Hollister AnchorFast device had an increased reading of force on the right cheekbone area (FS1) during each of the vertical and horizontal rotation phases of our testing. Airway complications are a recognized hazard during prone ventilation. ${ }^{2}$

Unfortunately, the statement in the first paragraph of the letter that "the increase in pressure exerted by the commercially available devices, which the authors reported as not clinically important" is incorrect. In fact, in the second paragraph of the discussion section, we specifically stated that "the force exerted on the patient's face by many of the commercial securing devices may result in discomfort and formation of pressure ulcers." ${ }^{1}$ We discussed that although there was no outlier in all of the factors tested, specific techniques/devices may prove more beneficial in certain circumstances.

We do agree and join with Gomaa and Branson in stressing the importance of therapists being aware of and vigilant in prevention of the development of pressure ulcers not only in the prone patient, but also in all patients who have artificial airways. Assessing skin integrity of all patients with artificial airways should be part of every patient evaluation regardless of the need for mechanical ventilation or prone positioning. Gomaa and Branson's reported experiences only further stress the need for continued evaluation of airway-securing procedures with more sophisticated modeling, as well as clinical observation.

Daniel F Fisher MSc RRT Respiratory Care Services Massachusetts General Hospital Boston, Massachusetts

\section{Robert M Kacmarek PhD RRT FAARC \\ Department of Anesthesiology, Critical Care and Pain Medicine Respiratory Care Services \\ Massachusetts General Hospital and Harvard Medical School Boston, Massachusetts}

Dr Kacmarek has disclosed relationships with Covidien, Hamilton Medical, General Electric, Newport, Dräger, and Maquet. Mr Fisher has disclosed no conflicts of interest.

DOI: $10.4187 /$ respcare.03980

\section{REFERENCES}

1. Fisher DF, Chenelle CT, Marchese AD, Kratohvil JP, Kacmarek RM. Comparison of commercial and noncommercial endotracheal tube-securing devices. Respir Care 2014;59(9):1315-1323.

2. Lee JM, Bae W, Lee YJ, Cho YJ. The efficacy and safety of prone positional ventilation in acute respiratory distress syndrome: updated study-level meta-analysis of 11 randomized controlled trials. Crit Care Med 2014;42(5):1252-1262. 